\title{
Population Growth and Fertility Patterns in an Old Order Amish Settlement: A 21-Year Follow-Up Study
}

\author{
Lawrence Greksa \\ Professor, Department of Anthropology \\ Case Western Reserve University \\ lpg2@case.edu
}

\begin{abstract}
This report describes population growth and fertility patterns in the Amish settlement centered in Geauga County, Ohio, and in particular, evaluates whether its fertility behavior is that of a natural fertility population. The dates of birth and death, location of household inside or outside the Geauga Settlement, and church status of all household members for the period up to January 1, 2014, were used to estimate population size, population structure, and various measures of fertility behavior. The results based on the 2014 directory were compared with similar data from the 1993 directory (Greksa, 2002) in order to estimate population growth rates and to determine if there has been change over time in population structure and fertility patterns.

The settlement consisted of 15,579 individuals distributed in 3,016 households in 107 districts as of January 1, 2014. The average annual growth rate between 1993 and 2014 was $3.0 \%$, with a doubling time of 23.0 years. Mean completed marital fertility was 6.9 live births, ranging from 0 to 17 births. There is a consistent pattern of decreasing total fertility rates (TFR) between 1924 and 2014. In particular, bivariate linear regression indicated that TFR decreased by about 1.7 births during this period. Despite the decrease in fertility over time, which is consistent with the use of birth control measures, the decrease in fertility appears to be independent of parity, suggesting that the Amish in the Geauga Settlement are still a natural fertility population.
\end{abstract}

Submitted October 5, 2020; accepted December 1, 2020; published March 24, 2021

https://doi.org/10.18061/jpac.v1i2.7953

Keywords: Amish, fertility, population growth, natural fertility

\section{Introduction}

Demographers have long been interested in natural fertility populations, or populations in which couples do not exhibit parity-dependent behaviors to limit fertility, particularly ceasing fertility once a desired family size is attained (Henry, 1961). Given their long-standing religious-based proscriptions against birth control, generally healthy lifestyle, and history of high fertility rates (Cross \& McKusick, 1970; McKusick et al., 1978; Hostetler, 1993), the Amish are generally assumed to be an example of a natural fertility population (Henry, 1980; Wood, 1994; Wasao \& Donnermeyer, 1996). An earlier examination of fertility in the Amish settlement centered in Geauga County, Ohio (henceforth, Geauga Settlement), for the period from January 1, 1908, to January 1, 1993, concluded that, despite exhibiting a clear pattern of gradually decreasing fertility over time, the settlement nevertheless met the requirements of a natural fertility population 
(Greksa, 2002). The present report follows up on that study, using data from a directory that covered the period up to January 1, 2014 (Miller, 2014). The purpose of the study is to determine how, if at all, fertility behavior has changed over 21 years, or approximately a generation. In particular, has the rate of population growth in the Geauga Settlement changed and is it still a natural fertility population?

\section{Materials and Methods}

The present report is based on the directory for the Geauga Settlement, which covers the period up to January 1, 2014 (Miller, 2014). The dates of birth and death of all household members, whether adult children resided in the Geauga Settlement, and the church status of all household members were provided in the directory and were used to estimate population size and fertility patterns. The results based on the 2014 directory were compared with similar data from the 1993 directory (Miller, 1993) in order to determine if there has been change over time in fertility patterns.

Seventy-four pregnancies were identified as stillbirths in the 1993 directory (Greksa, 2002) and an additional 18 births (out of 30) with the same dates of birth and death who were not given a name were assumed to be likely stillbirths. Unlike in the 1993 directory, no births were specifically identified as stillbirths in the 2014 directory. A conservative approach was taken, and all births with the same dates of birth and death that were not given names (47 out of 118) were assumed to be stillbirths. Births labeled as stillbirths were not used in the calculation of fertility rates (Wood, 1994).

Completed marital fertility rates were based on 1,051 living married women who were at least 45 years old by January 1, 2014, and who were married before the age of 45 years. Changes over time in fertility were evaluated by calculating age-specific and total marital fertility rates in seven 10-year cohorts, with the oldest cohort born between January 1, 1924, and December 31, 1933. There was an insufficient number of women in older cohorts to permit calculation of fertility rates. The three youngest cohorts (Table 4) have not completed their fertilities. In order to estimate their eventual total fertility rate, it was assumed that they would exhibit the same fertility pattern as the most recent previous cohort that had completed that age group.

All continuous variables were tested for normality with t-tests for skewness and kurtosis, using an alpha of 0.05 . Mean and standard deviation were used to describe normally distributed variables while the median and range were used for non-normal variables. Statistical analyses were performed with SPSS for Windows, Version 26.

\section{Results}

The total population size of the Geauga Settlement as of January 1, 2014, was 15,579 , or $87 \%$ larger than the 1993 population (Table 2). The average annual growth rate between 1993 and 2014

was $3.0 \%$ (doubling time of 23.0 years). The age and sex structures of the Geauga Settlement are described in Table 1. 
Table 1

Age and Sex Distribution of the Geauga Settlement as of January 1, 2014

\begin{tabular}{crrrr}
\hline & \multicolumn{3}{c}{ Males } & \multicolumn{2}{c}{ Females } \\
\cline { 2 - 5 } Age $(\mathrm{yrs})$ & \multicolumn{1}{c}{$n$} & $\%$ & \multicolumn{1}{c}{$n$} & $\%$ \\
\hline $0-4$ & 1,165 & 14.8 & 1,121 & 14.5 \\
$5-9$ & 1,185 & 15.1 & 1,108 & 14.4 \\
$10-14$ & 1,038 & 13.2 & 1,036 & 13.4 \\
$15-19$ & 876 & 11.1 & 865 & 11.2 \\
$20-29$ & 1,267 & 16.1 & 1,278 & 16.6 \\
$30-39$ & 909 & 11.6 & 811 & 10.5 \\
$40-49$ & 566 & 7.2 & 567 & 7.4 \\
$50-59$ & 378 & 4.8 & 380 & 4.9 \\
$60-69$ & 288 & 3.7 & 302 & 3.9 \\
$70-79$ & 139 & 1.8 & 159 & 2.1 \\
$80-89$ & 48 & 0.6 & 74 & 1.0 \\
$90-99$ & 6 & 0.1 & 13 & 0.2 \\
Total & $\mathbf{7 , 8 6 5}$ & & $\mathbf{7 , 7 1 4}$ & \\
\hline
\end{tabular}

Basic demographic data on the settlement in 1993 and 2014 are provided in Table 2. The population was distributed in 3,016 households in 107 districts in 2014. Ninety-four households were occupied by single females, 21 by single males, and 7 by single siblings sharing a home. The number of households per congregation varied from 18 to 44, with a mean size of 28.1 households. Congregation size varied from 65 to 247 individuals, with a mean size of 145.6 individuals. Median household size was 5.0, varying from 1 to 17 individuals. The sex ratio was 1.02 , and $42.7 \%$ of the population was less than 15 years old. 
Table 2

Selected Demographic Variables in the Geauga Settlement

\begin{tabular}{lrr}
\hline & \multicolumn{1}{c}{1993} & \multicolumn{1}{c}{2014} \\
\cline { 2 - 3 } Population size & 8,345 & 15,579 \\
Households & 1,608 & 3,016 \\
Congregations & 54 & 107 \\
Sex ratio & 1.00 & 1.02 \\
$<15$ yrs old & $46.0 \%$ & $42.7 \%$ \\
Congregation size & & \\
$\quad \bar{X}(\mathrm{SD})$ & $154.3(38.7)$ & $145.0(36.6)$ \\
$\quad$ Range & $84-238$ & $65-247$ \\
Households per congregation & & \\
$\quad \bar{X}$ (SD) & $29.8(7.2)$ & $28.1(6.9)$ \\
$\quad$ Range & $13-42$ & $18-44$ \\
Household size & & \\
$\quad$ Median, range & $5.0(1-17)$ & $5.0(1-17)$ \\
$\bar{X}$ (SD) & $5.1(3.0)$ & $5.1(3.0)$ \\
\hline
\end{tabular}

Various measures of fertility in the Geauga settlement are included in Table 3. Mean completed marital fertility in 2014 in women 45 years and older who were married before the age of 45 years was 6.9 live births, ranging from 0 to 17 births. Considering only this cohort of women who have completed their fertility, $3.9 \%$ were childless, $20.2 \%$ had 10 or more live births, and their last child was born at an average age of 37.0 years. The twinning rate in the total sample of married women was 12.0 per 1,000 pregnancies resulting in a live birth. The median interval between a wedding and a couple's first birth was 1.00 years, the median interval between the $1 \mathrm{st}$ and $2 \mathrm{nd}$ births was about 1.5 years while the median intervals between the 4th and 5th, 7th and 8th, and 10th and 11th births were all about 2.0 years. Although not reported here, similar intervals are found within each 10 -year cohort. 
Table 3

Selected Fertility Variables in the Geauga Settlement

\begin{tabular}{|c|c|c|}
\hline & 1993 & 2014 \\
\hline \multicolumn{3}{|l|}{ Married women $>45$ years } \\
\hline Completed marital fertility [(SD)] & $7.7(3.6)$ & $6.9(3.2)$ \\
\hline Childlessness & $3.0 \%$ & $3.9 \%$ \\
\hline Age at birth of last child [(SD)] & $38.0(5.2)$ & $37.0(5.4)$ \\
\hline$\geq 10$ births & $28.0 \%$ & $20.2 \%$ \\
\hline Still births per 1,000 pregnancies & 22.7 & 7.6 \\
\hline Twinning rate per 1,000 pregnancies & 13.9 & 12.3 \\
\hline \multicolumn{3}{|l|}{ Birth intervals (yr) [median (range)] } \\
\hline Wedding to 1st birth & $1.00(0.60,12.40)$ & $1.00(0.60,16.60)$ \\
\hline 1st to 2 nd birth & $1.45(0.60,13.00)$ & $1.50(0.60,11.80)$ \\
\hline 4th to 5 th birth & $1.92(0.50,10.30)$ & $2.00(0.70,22.20)$ \\
\hline 7th to 8th birth & $1.97(0.50,9.40)$ & $2.10(0.80,9.40)$ \\
\hline 10th to 11 th birth & $1.90(0.70,8.40)$ & $2.00(1.00,8.40)$ \\
\hline
\end{tabular}

Median ages of men and women at their first marriage and the median age of mothers at their first and last births by 10-year cohorts are included in Tables 4 and 5. The age of mothers at the birth of their last child was only calculated for women who had completed their fertility. The median ages of fathers and mothers at their first marriage were fairly consistent over time, with women being about one year younger than their husbands. Excluding the oldest cohort (which is the cohort with the smallest sample size), mothers gave birth to their first child about one year after marriage. Finally, the median age of mothers at the birth of their last child varied from about 39 to 41 years in the two oldest cohorts, but then was consistently somewhat younger, or about 37 years, in the next three cohorts.

Table 4

Median Ages at First Marriage of Mothers and Fathers, by Birth Cohort

\begin{tabular}{lccccc}
\hline & \multicolumn{2}{c}{ Father's age at first marriage } & \multicolumn{2}{c}{ Mother's age at first marriage } \\
\cline { 2 - 6 } & $\mathrm{N}$ & Median (Range) & $\mathrm{N}$ & Median (Range) \\
\cline { 2 - 6 } 1 Jan 1918 to 31 Dec 1927 & 47 & $22.8(19.5,31.5)$ & 37 & $21.7(19.4,32.8)$ \\
1 Jan 1928 to 31 Dec 1937 & 111 & $22.6(18.4,39.3)$ & 102 & $21.0(16.2,30.3)$ \\
1 Jan 1938 to 31 Dec 1947 & 229 & $22.3(18.5,36.0)$ & 205 & $20.9(17.8,64.7)$ \\
1 Jan 1948 to 31 Dec 1957 & 323 & $22.8(18.0,56.5)$ & 322 & $21.0(17.3,47.6)$ \\
1 Jan 1958 to 31 Dec 1967 & 402 & $22.6(17.7,43.1)$ & 391 & $21.1(16.7,45.6)$ \\
1 Jan 1968 to 31 Dec 1977 & 641 & $22.1(18.5,43.2)$ & 601 & $21.1(17.3,38.0)$ \\
1 Jan 1978 to 31 Dec 1987 & 850 & $22.3(18.5,34.8)$ & 841 & $20.9(17.9,32.8)$ \\
1 Jan 1988 to 31 Dec 1997 & 290 & $21.8(18.5,25.4)$ & 409 & $20.8(17.9,25.6)$ \\
\hline
\end{tabular}


Table 5

Median Ages of Mothers at the Birth of Their First and Last Child, by Birth Cohort

\begin{tabular}{lccccc}
\hline & \multicolumn{2}{c}{ Mother's age at first birth } & \multicolumn{2}{c}{ Mother's age at last birth } \\
\cline { 2 - 6 } & $\mathrm{N}$ & Median (Range) & $\mathrm{N}$ & Median (Range) \\
\cline { 2 - 6 } 1 Jan 1918 to 31 Dec 1927 & 37 & $23.5(21.0,37.8)$ & 37 & $40.9(27.1,47.5)$ \\
1 Jan 1928 to 31 Dec 1937 & 103 & $22.1(16.4,32.6)$ & 103 & $38.9(21.6,47.1)$ \\
1 Jan 1938 to 31 Dec 1947 & 199 & $21.9(18.0,40.8)$ & 199 & $37.4(19.4,57.0)$ \\
1 Jan 1948 to 31 Dec 1957 & 314 & $22.3(17.2,40.7)$ & 314 & $37.3(19.7,53.1)$ \\
1 Jan 1958 to 31 Dec 1967 & 380 & $22.3(17.4,38.7)$ & 380 & $37.3(20.8,51.1)$ \\
1 Jan 1968 to 31 Dec 1977 & 594 & $22.2(17.3,37.2)$ & --- & --- \\
1 Jan 1978 to 31 Dec 1987 & 785 & $22.0(16.9,34.7)$ & --- & --- \\
1 Jan 1988 to 31 Dec 1997 & 271 & $21.6(15.9,25.8)$ & --- & --- \\
\hline
\end{tabular}

Age-specific fertility rates (ASFR) and total fertility rates (TFR) for 2,922 married women are provided by 10 -year cohorts in Table 6 . There is a fairly consistent pattern of decreasing total fertility rates between 1924 and 2014. Bivariate linear regression indicated that TFR decreased by 0.29 births per decade during this period (TFR $=8.30-0.288$ (decade), $\mathrm{r}^{2}=73.2 \%$ ), or a decrease overall of about 1.7 births between 1924 (8.62) and 2014 (6.33). The two youngest cohorts have somewhat lower ASFRs than found in older cohorts. TFR by cohort is described for the combined 1993 and 2014 directories in Figure 1, which increases the time frame of TFR from 1909 to 1987. In this case, TFR in the 2014 population was calculated using the same cohorts as in the 1993 publication (Greksa, 2002) in order to facilitate the linking of the TFR calculations of the two directories. 
Table 6

Age-Specific and Total Fertility Rates (TFR) of Married Women, by Birth Cohort

\begin{tabular}{|c|c|c|c|c|c|c|c|c|c|c|}
\hline \multirow[b]{2}{*}{ Birth Cohort } & \multirow[b]{2}{*}{$\mathrm{N}$} & \multicolumn{7}{|c|}{ Age Category (yrs) } & \multirow{2}{*}{$\begin{array}{l}\text { Cumu- } \\
\text { lative } \\
\text { fertility }\end{array}$} & \multirow[b]{2}{*}{ TFR } \\
\hline & & $15-19$ & $20-24$ & $25-29$ & $30-34$ & $35-39$ & $40-44$ & $45-49$ & & \\
\hline $\begin{array}{l}\text { 1 Jan } 1924 \text { to } \\
\text { 31 Dec } 1933\end{array}$ & 84 & 0.019 & 0.369 & 0.509 & 0.369 & 0.299 & 0.145 & 0.014 & 8.62 & 8.62 \\
\hline $\begin{array}{l}1 \text { Jan } 1934 \text { to } \\
31 \text { Dec } 1943\end{array}$ & 159 & 0.031 & 0.400 & 0.422 & 0.323 & 0.213 & 0.075 & 0.005 & 7.35 & 7.35 \\
\hline $\begin{array}{l}1 \text { Jan } 1944 \text { to } \\
31 \text { Dec } 1953\end{array}$ & 288 & 0.030 & 0.338 & 0.400 & 0.316 & 0.215 & 0.081 & 0.010 & 6.95 & 6.95 \\
\hline $\begin{array}{l}1 \text { Jan } 1954 \text { to } \\
31 \text { Dec } 1963\end{array}$ & 343 & 0.037 & 0.345 & 0.399 & 0.320 & 0.213 & 0.075 & 0.009 & 6.99 & 6.99 \\
\hline $\begin{array}{l}1 \text { Jan } 1964 \text { to } \\
31 \text { Dec } 1973\end{array}$ & 521 & 0.037 & 0.370 & 0.420 & 0.316 & 0.203 & 0.070 & 0.000 & 7.09 & 7.13 \\
\hline $\begin{array}{l}1 \text { Jan } 1974 \text { to } \\
31 \text { Dec } 1983\end{array}$ & 745 & 0.028 & 0.371 & 0.368 & 0.284 & 0.000 & 0.000 & 0.000 & 5.25 & 6.66 \\
\hline $\begin{array}{l}1 \text { Jan } 1984 \text { to } \\
31 \text { Dec } 1993\end{array}$ & 782 & 0.026 & 0.305 & 0.000 & 0.000 & 0.000 & 0.000 & 0.000 & 1.66 & 6.33 \\
\hline
\end{tabular}

\section{Discussion}

The Amish have long been noted for their large family sizes and, at least recently, their high retention rates (Greksa \& Korbin, 2002; Meyers, 1991), resulting in rapid population growth. Donnermeyer (2015) reviewed the data on Amish population growth rates and found estimates of population doubling time varying from about 20.0 to 24.0 years (Cross, 1976; Donnermeyer et al., 2013; Donnermeyer \& Cooksey, 2010; Hostetler, 1993; Kraybill et al., 2013), although he argued that the methodology for the calculation of these rates was not always clear. Doubling time in the Geauga Settlement between 1993 and 2014 (23 years) falls within this range. 


\section{Figure 1}

Total Fertility Rate by Cohort Based on the 1993 and 2014 Geauga Settlement Directories

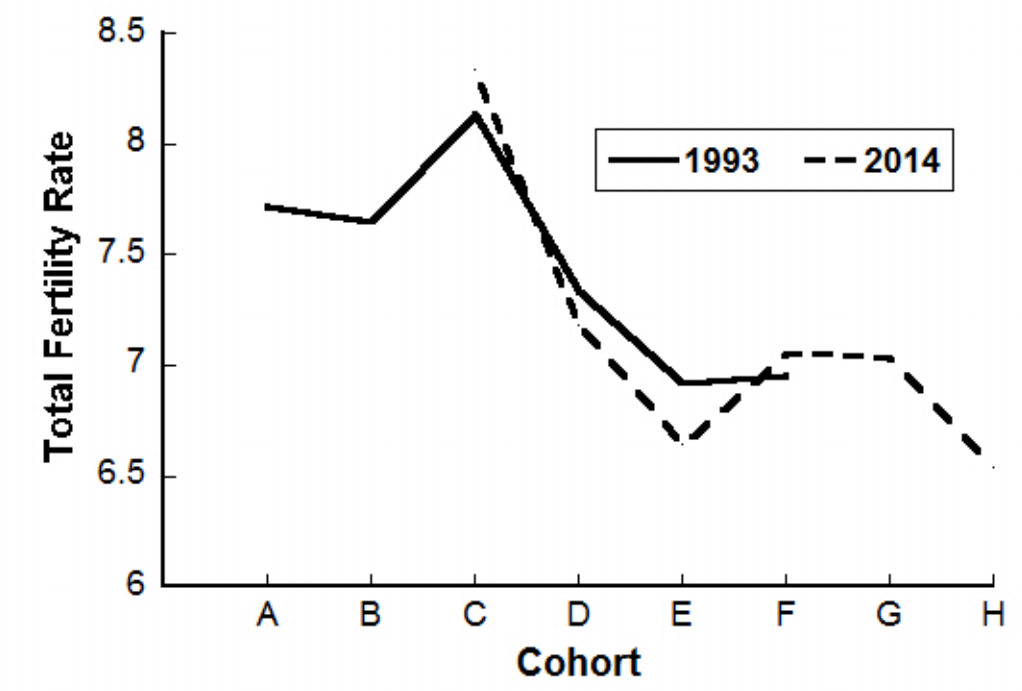

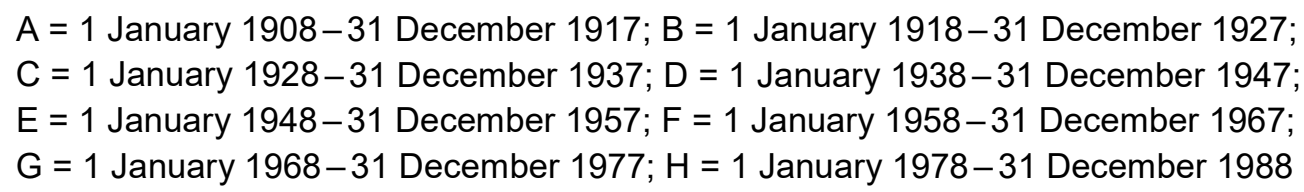

Donnermeyer (2015) argued that, although reasonably accurate headcounts can be obtained from settlement directories, directories are not available for all settlements and, even when they are available, they are not necessarily for the same time period. In the absence of such a database, he argued that reasonable estimates of the total size of the Amish population, and thus rates of increase in the size of the Amish population, can be best estimated from the increase in the number of households between two time periods, as long as one assumes a fairly constant average family size. The evidence in the current study at least suggests that the assumption of a fairly constant average household size over time, or at least recent time, is reasonable since there was no change in median household size between the 1993 and 2014 directories of the Geauga Settlement (Table 2). Median household sizes are presented in Table 2 because this variable was significantly right skewed in both the 1993 and 2014 directories. However, estimates of total population size of the Geauga Settlement would only change slightly if one relied on mean household sizes which, though skewed, were actually only slightly larger than the median and, most important, were also identical in the 1993 and 2014 directories (Table 2).

Based on population sizes derived from individual counts from directories, the Geauga Settlement increased at an annual rate of 3.0\% between 1993 and 2014 . How does the growth rate of the Geauga Settlement compare to other settlements? Based on changes in the number of households between 2009 and 2014 in 62 settlements that reported end-of-year statistics for all of 
the years from 2009 to 2014, Donnermeyer (2015) estimated an average $4.0 \%$ increase in number of households with a consequent doubling time of 17.7 years, or a considerably faster rate of growth than in the Geauga Settlement. However, Donnermeyer (2015) recognized that his sample included settlements varying in parameters that would likely influence growth rates, particularly the age and size of settlements. It would not be surprising, for example, if newer, and thus smaller, settlements increased in size at a faster rate than larger, well-established settlements. He therefore also provided estimates based on these two criteria. In 39 settlements with $\geq 100$ households, there was a $2.6 \%$ increase in households, with a doubling time of 26.8 years, while in 70 settlements founded before 1980, there was a $2.0 \%$ increase in households and a 34.6-year doubling time. In other words, taking into account the age and size of settlements resulted in a substantial reduction in growth rates.

The rate of population increase in the Geauga Settlement between 1993 and 2014 was less than the rate based on all settlements and greater than the rate predicted for settlements with $\geq 100$ households and an establishment date prior to 1980 . In particular, the $3.0 \%$ rate of growth in the Geauga Settlement was $15.4 \%$ greater than the estimate for settlements with $\geq 100$ households (3,016 households in the Geauga Settlement) and was 50.0\% greater than in settlements established prior to 1980 (the Geauga Settlement was established in 1886). Why the rate of growth in the Geauga Settlement is faster than predicted by Donnermeyer's (2015) average for settlements with $\geq 100$ households or that were established before 1980 is not clear. The restrictions on age and size of settlements utilized by Donnermeyer (2015) were reasonable but encompass substantial variability. More discrimination in these factors might be useful. For example, it would not be surprising if the rates of growth in the four largest settlements (Holmes County, Ohio; Lancaster County, Pennsylvania; Elkhart-LaGrange, Indiana; and Geauga County, Ohio), all of which are much larger than 100 households and were established long before 1980, differ from much smaller and more recent settlements. Other factors, and there might be more, which could potentially influence growth rates are differences in levels of tourism, population density, occupational patterns, and availability of affordable land. More refined analyses of investigation of the factors associated with differences in growth rates among settlements would be informative.

Estimates of growth rate in the Geauga Settlement between 1993 and 2014 based on changes in the number of households, as suggested by Donnermeyer (2015) when individual counts are not available, were a 3.0\% annual growth rate with a 22.8-year doubling time. These estimates are almost identical to values based on individual counts for the Geauga Settlement, or 3.0\% and 23.0 years. It would, of course, be useful to have similar confirmations from other settlements but, nevertheless, this finding for the Geauga Settlement strongly supports Donnermeyer's (2015) argument for the use of household counts to estimate population size and population growth rates when directories are not available. Median household sizes are presented in Table 2 because this variable was significantly right skewed in both the 1993 and 2014 directories. However, the conclusion would not change if one relied on mean household sizes which, though skewed, were only slightly larger than the median and, most important, were also identical in the 1993 and 2014 
directories (Table 2). Mean household sizes would thus result in slightly larger total population size estimates but no change in population growth rates.

When comparing demographic characteristics of the Geauga Settlement between 1993 and 2014 (Table 2), there were minor differences in sex ratio, congregation size, and households per congregation, and no change in household size. The fact that household size did not change at all is surprising since one might predict that the decrease in TFR observed in the Geauga Settlement between 1993 and 2014 (Table 6 and Figure 1) would be associated with a decrease in household size (Table 2). Why household size did not decrease is not clear, but one possibility is that the decrease in TFR was primarily the result of a substantial decrease in the proportion of females having larger-than-average family sizes. For example, there was an almost 30\% decrease between 1993 and 2014 in women who had 10 or more births (Table 3).

As noted earlier, there was a clear decrease over time in various measures of fertility. For example, mean completed marital fertility in women 45 years and older decreased from 7.7 to 6.9 , or by $11.6 \%$, between 1993 and 2014, and women with 10 or more births decreased by $27.9 \%$. In addition, the proportion of the population that is less than 15 years old decreased by $7.2 \%$ (Table 3 ), while the rate of childlessness increased from $3.0 \%$ to $3.9 \%$, or by $30.0 \%$. This is a substantial proportional increase in childlessness. It is not clear why but it may simply reflect random variation in rates in small demographic samples since it is within the range of variation found in Amish populations. Cross and McKusick (1970), for example, reported a childlessness rate of 3.8\%.

This decrease in fertility, which is occurring without a change in the age at first marriage or age at the birth of the first child, is a continuation of a long-standing pattern of change over time (Figure 1). Bivariate regression analysis in the earlier study of the Geauga Settlement indicated a decrease in TFR of 0.19 births per decade between 1908 and 1967. The present study found a decrease in TFR of 0.29 births per decade between 1924 and 1993, suggesting that the rate of decrease in TFR is increasing in the Geauga Settlement. The fact that the ASFRs for the youngest age groups in the two most recent cohorts (1974-1983 and 1984-1993) are generally somewhat lower than in previous cohorts suggests that this pattern of decreasing fertility may well continue and even perhaps accelerate, resulting in TFRs for the youngest cohorts that are smaller than the estimated TFRs provided in Table 6.

There are undoubtedly multiple factors playing a role in the consistent decrease in TFR in the Geauga Settlement. One of these is presumably the transition away from agriculture, particularly in the larger and older settlements. The Amish have been undergoing an economic transition away from agriculture for decades, beginning about 1950 (Kraybill et al., 2013). For example, 31.1\% of men in the Geauga Settlement reported being farmers in 1973, 16.8\% were farming in 1993 (Greksa, 2002), and only 5.5\% reported being farmers in 2014. Kraybill et al. (2013) reasonably argue that this transition to working off the farm is often associated with a more modern worldview, leading some Amish to be more likely to practice some method of family planning.

Mean completed marital fertility in the Geauga Settlement in 2014 (Table 3) is similar to that found in other settlements (Cross \& McKusick, 1970; Ericksen et al., 1979; Meyers, 1991; Wasao, 
1995; Hewner, 1997; Kraybill et al., 2013). As noted earlier, given their strong proscriptions against birth control and long history of high fertilities, the Amish have been characterized as an example of a natural fertility population, or one in which families do not exhibit parity-dependent behaviors to limit fertility (Espenshade, 1971; Ericksen et al, 1979; Henry, 1980; Wood et al., 1994). The consistent decrease in fertility in the Geauga settlement over the last 8 decades (Table 6 and Figure 1) raises the possibility that the Amish in at least this settlement are no longer a natural fertility population. However, a population can limit their fertility and still be a natural fertility population as long as the decrease is not parity-dependent, which essentially means families do not use stopping behaviors once they have achieved a desired family size. If this was occurring in the Geauga Settlement, one would expect a decrease over time in the age at which women have their last child, but that has not yet happened. The mean age at which women had their last child did decrease by one year between 1993 and 2014 (Table 3) but this difference is not close to being statistically significant $(t=11.7, p>.05)$. The data on age at the birth of their last child is, of course, based on women who have completed their fertilities. Only time will tell if women who are now younger than 45 years old will stop their fertility at an earlier age than older cohorts.

If the decrease in fertility is not due to stopping behaviors, how does one explain it? Women could begin having children at an older age but there is no evidence for that occurring in the Geauga Settlement since the age of mothers at the birth of their first child, as well as the interval between their wedding and their first birth, did not change between 1993 and 2014 (Table 3). One obvious mechanism for decreasing fertility without stopping behaviors would be to increase the interval between births through some mode of birth control. It does appear that some Amish, although how many is not clear, do utilize contraceptive methods (Kraybill et al., 2013; Markle \& Pasco, 1977). However, there are no differences in birth intervals between the 1993 and 2014 directories. In both directories, there is a consistent median interval of about 1.0 years between wedding and first birth, 1.5 years between the first and second births, and about 2.0 years for other intervals (Table 3). A similar pattern was found when examining birth intervals by 10 -year cohorts. Given that there is no evidence for stopping behaviors or for an increase in birth intervals, it is reasonable to conclude that the Amish in the Geauga Settlement are still meeting the requirements of a natural fertility population.

\section{References}

Cross, H. E. (1976). Population studies and the Old Order Amish. Nature, 262, 17-20. https://doi.org/10.1038/262017a0

Cross, H. E., \& McKusick, V. A. (1970). Amish demography. Social Biology, 17(2), 83-101. https://doi.org/10.1080/19485565.1970.9987850

Donnermeyer, J. F. (2015). Doubling time and population increase of the Amish. Journal of Amish and Plain Anabaptist Studies, 3(1), 94-109. https://doi.org/10.18061/1811/69364 
Donnermeyer, J. F., \& Cooksey, E. C. (2010). On the recent growth of new Amish settlements. Mennonite Quarterly Review, 84(2), 181-207.

Donnermeyer, J. F., Anderson, C., \& Cooksey, E. C. (2013). The Amish population: County estimates and settlement patterns. Journal of Amish and Plain Anabaptist Studies, 1(1), 72109. https://doi.org/10.18061/1811/54896

Ericksen, E. P., Ericksen, J. A., \& Hostetler, J. A. (1980). The cultivation of the soil as a moral directive: Population growth, family ties, and the maintenance of community among the Old Order Amish. Rural Sociology, 45(1), 49-68.

Ericksen, J. A., Ericksen, E. P., Hostetler, J. A., \& Huntington, G. E. (1979). Fertility patterns and trends among the Old Order Amish. Population Studies, 33(2), 255-276.

https://doi.org/10.1080/00324728.1979.10410441

Espenshade, T. J. (1971). A new method for estimating the level of natural fertility in populations practicing birth control. Demography, 8, 525-536. https://doi.org/10.2307/2060688

Greksa, L. P. (2002). Population growth and fertility patterns in an Old Order Amish settlement. Annals of Human Biology 29(2), 192-201. https://doi.org/10.1080/03014460110075684

Greksa, L. P., \& Korbin, J. E. (2002). Key decisions in the lives of the Old Order Amish: Joining the church and migrating to another settlement. Mennonite Quarterly Review, 76(4): 373-398.

Henry, L. (1961). Some data on natural fertility. Eugenics Quarterly, 8(2), 81-91. https://doi.org/10.1080/19485565.1961.9987465

Henry, L. (1980). Some remarks on the paper by Julia Ericksen et al., "Fertility patterns and trends among the Old Order Amish." Population Studies, 34(3), 564. https://doi.org/10.2307/2174812

Hewner, S. J. (1997). Biocultural approaches to health and mortality in an Old Order Amish community. Collegium Anthropologicum, 21(1), 67-82.

Hostetler, J. A. (1955). Old World extinction and New World survival of the Amish: A study of group maintenance and dissolution. Rural Sociology, 20, 212-219.

Hostetler, J. A. (1993). Amish society (4th ed.). Johns Hopkins University Press.

Kraybill, D. B., Johnson-Weiner, K. M., \& Nolt, S. M. (2013). The Amish. Johns Hopkins University Press.

Markle, G. E., \& Pasco, S. (1977). Family limitation among the Old Order Amish. Population Studies, 31(2), 267-280. https://doi.org/10.2307/2173918

McKusick, V. A., Hostetler, J. A., \& Egeland, J. A. (1978). Genetic studies of the Amish: Background and potentialities. In V. A. McKusick (Ed.), Medical genetic studies of the Amish: Selected Papers (pp. 3-22). Johns Hopkins University Press.

Meyers, T. J. (1991). Population growth and its consequences in the Elkhart-LaGrange Old Order Amish settlement. Mennonite Quarterly Review, 65(3), 308-321.

Meyers, T. J. (1994). The Old Order Amish: To remain in the faith or to leave. Mennonite Quarterly Review, 68(3), 378-395. 
Miller, A. J. (2014). Ohio Amish directory: Geauga County and vicinity, 2014 edition. Carlisle Printing.

Miller, P. E. (1993). Ohio Amish directory: Geauga County and vicinity, 1993 edition. Carlisle Printing.

Wasao, S. W. (1995). Fertility differentials among three Amish affiliations [Unpublished doctoral dissertation]. Ohio State University.

Wasao, S. W., \& Donnermeyer, J. F. (1996). An analysis of factors related to parity among the Amish in Northeast Ohio. Population Studies, 50(2), 235-246. https://doi.org/10.1080/0032472031000149326

Wood, J. W. (1994). Dynamics of human reproduction: Biology, biometry, demography. Aldine de Gruyther.

Wood, J. W., Holman, D. J., Yashin, A. I., Peterson, R. J., Weinstein, M., \& Chang, M.-C. (1994). A multistate model of fecundability and sterility. Demography, 31, 403-426. https://doi.org/10.2307/2061750 